\title{
Photovoltaics And its Potential Application in THE Production OF ELECTRICITY
}

\author{
Pavel Chrobak, Martin Zalesak, Stanislav Sehnalek
}

Tomas Bata University in Zlin, Faculty of Applied Informatics, Nad Stranemi 4511, 76005 Zlin, Czech Republic

\begin{abstract}
In presented paper authors summarize potential of various options for the application of photovoltaic systems. On this continues other part which is focused on the influence of slope and orientation to the production of electricity by photovoltaic panels. It includes the example of electricity production at an existing system in year 2014. The last part of the paper examine the influence of surface contamination on photovoltaic panels and their effectiveness. At the end of the presented paper is summarized findings of the authors.
\end{abstract}

Keywords: photovoltaic panels; electricity; production of electricity; effectivnes of PV panels;
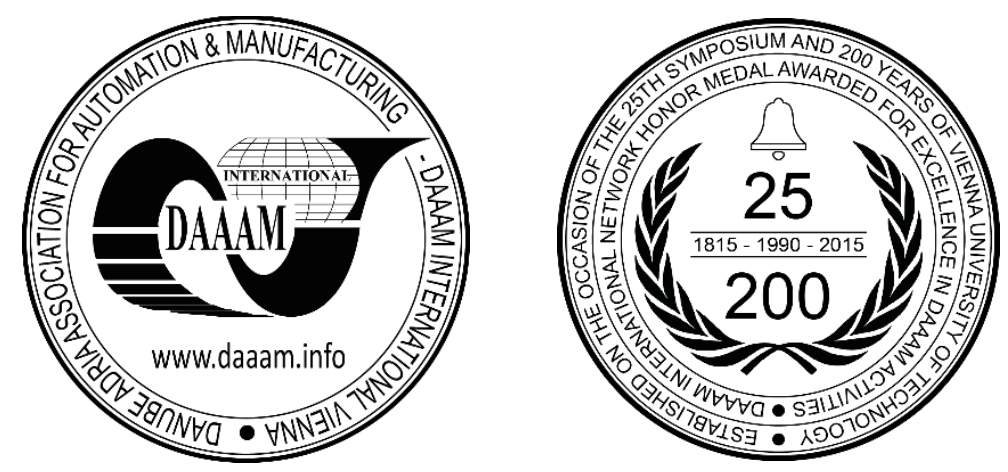

This Publication has to be referred as: Chrobak, P[avel]; Zalesak, M[artin] \& Sehnalek, S[tanislav] (2016). Photovoltaics and its Potential Application in the Production of Electricity, Proceedings of the 26th DAAAM International Symposium, pp.1032-1037, B. Katalinic (Ed.), Published by DAAAM International, ISBN 978-3-902734-07-5, ISSN 1726-9679, Vienna, Austria

DOI: $10.2507 / 26$ th.daaam.proceedings.145 


\section{Introduction}

In recent years, is more and more increasing demand for electricity, which is obtained from fossil fuel sources. The disadvantage of these energy sources is that they weigh heavily on the environment and thus increases the pressure on scientists who are exploring new technologies for electricity production from clean renewable sources such as solar, wind energy. Solar energy is the oldest primary source of energy. It is a source of clean, renewable energy that is available in all parts of the world but it entails some disadvantages and the high cost of installing PV systems and their low efficiency [1], [2]. The planet permanently impinges on the radiation power of about $\mathrm{P}=1.810^{17} \mathrm{~W}$ and only with slight variations depending on the activity of the sun and the time of year. Although we can use only a portion of this energy there would be enough to cover all the energy needs of humanity with the help of photovoltaic panels, which would occupy an area of about $1000 \times 1000$ square kilometers that is about one tenth of the area of the Sahara [1]. So far, however, this energy is used as an additional resource that is most applicable in areas where electrification network does not interfere with nor would be payable to build it. This post will focus on different fields of application of the photovoltaic system and the issue of the impact and the inclination of photovoltaic panels to produce electricity.

\section{The principle of photovoltaic conversion}

Photovoltaic is a method for the direct conversion of sunlight into electricity by using the photoelectric effect on large semiconductor photodiodes (photovoltaic cells). The individual photodiodes are called photovoltaic cells and are usually attached into larger units (photovoltaic panels). The simplest photodiodes consists of two semiconductors with a different type of electrical conductivity. In one of the layers the material of the type $\mathrm{N}$ predominate negatively charged electrons, while the second layer of material P predominate "holes" which are essentially blanks which readily accept electrons. At the point where these two layers meet with a $\mathrm{P}-\mathrm{N}$ junction where there is a pair of electrons with holes, thereby creating an electric field that prevents other electrons move from the $\mathrm{N}$ - layer to the P layer [4]. Normally, the electrons in the semiconductor material are firmly bonded to the atoms of the crystal grid and the material is then nonconductive. By adding a very small amount of an element with a greater number of valence electrons to the crystal creates a region of conductivity of the type $\mathrm{N}$, in which free electrons exist creates electrical charge. Conversely an impurity element with a reduced number of valence electrons creates a region with conductivity of the $\mathrm{P}$ type, in which the crystal grid range hole are as without electrons. If the semiconductor material capture of a photon of sufficient energy, it results in creation of one electron-hole pair [5], [6]. If this circuit is closed they begin to move in the opposite direction of the charge carriers, electrons to the negative electrode, the positive holes, as shown in Fig. 1.

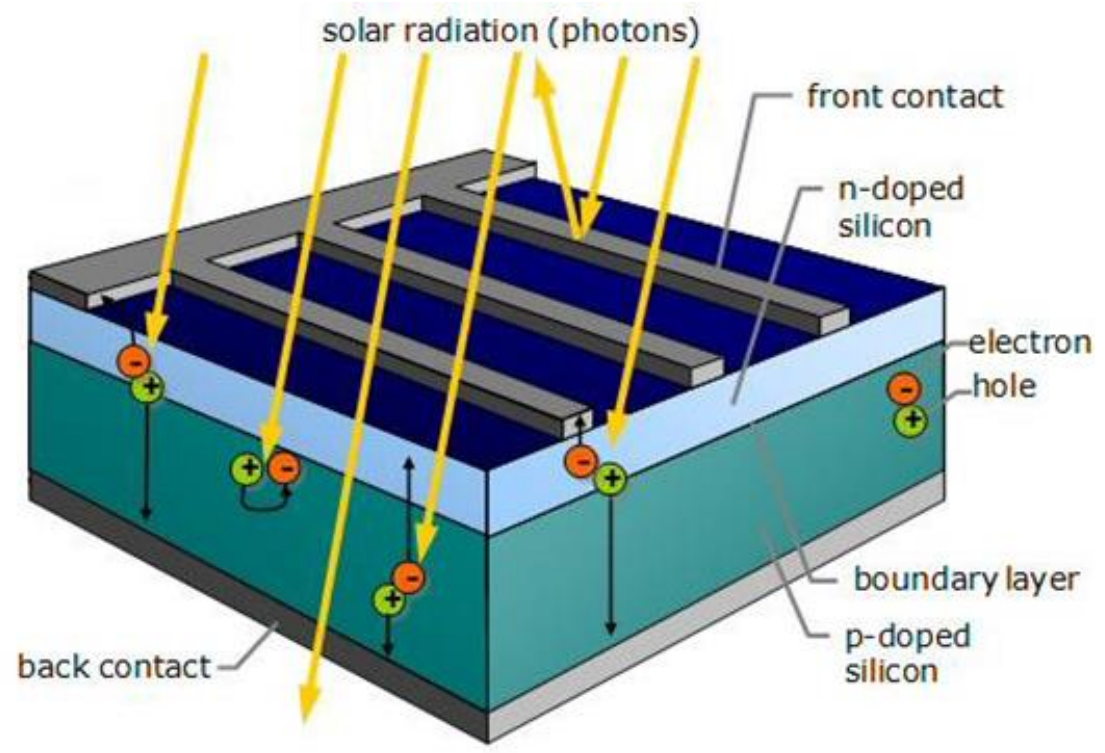

Fig. 1. Structure of a photovoltaic cell [2]

\section{Division solar cells}

Solar cells are divided into mono crystalline, polycrystalline and thin film. Monocrystalline cells are formed from thin sheets of semiconductor material, and their electiveness is typically between 13-18\%. Although their production is costly to the high consumption of silicon. It makes up the largest share of the market that is around $85 \%$. Another group on market is the polycrystalline articles. They are less expensive because its production does not need such a quantity of silicon, its normal electiveness is lower, about $12 \%$ to $16 \%$. The last group consists of thin articles, whose electiveness is normally in the range of 7-9\% [6], [7]. 


\section{Photovoltaic systems}

Depending on the application, we can divided photovoltaic systems into the following groups and applications on small systems, insular systems, and network systems. Minor applications occupy the smallest market share of photovoltaic panels. They are used mainly as a source of electrical power in devices that are not too demanding on energy as are calculators, for example. It also serves as a power source for the batteries, which are then used to charge a variety of portable devices (phones, laptops), if it is not available an electric grid for some reason. Island systems are mainly used in places where it is not available the public electricity network and can be divided into systems with direct power where it is a simple connection of solar panel with the appliance. These applications are not commonly used as the machine operates only when a sufficient intensity of solar radiation occur. There are mostly used for battery charging small devices to power irrigation systems for ventilation of enclosed spaces. Furthermore, on the island hybrid systems, which are used primarily in areas where the demand for year-round operation in winter and on cloudy days, solar panels deliver significantly less electricity than in the sunny summer days. For this reason, it is essential to design these systems so that it could supply enough electricity in winter. These performance requirements considerably inflate the final price. For this reason, photovoltaic systems complemented alternative source of electrical energy, which can be, for example, wind power, hydroelectric power, cogeneration unit, fuel generator. The last group consists of systems with energy storage. This type of system is independent of the main network and this system requires extra batteries, which are used to store electrical energy for when the solar panels do not supply enough electricity. Such insular system consists of photovoltaic panels, battery charge controller, battery, inverter - converter for connecting common network appliances as shown in the following Figure 2 [8], [9], [10].

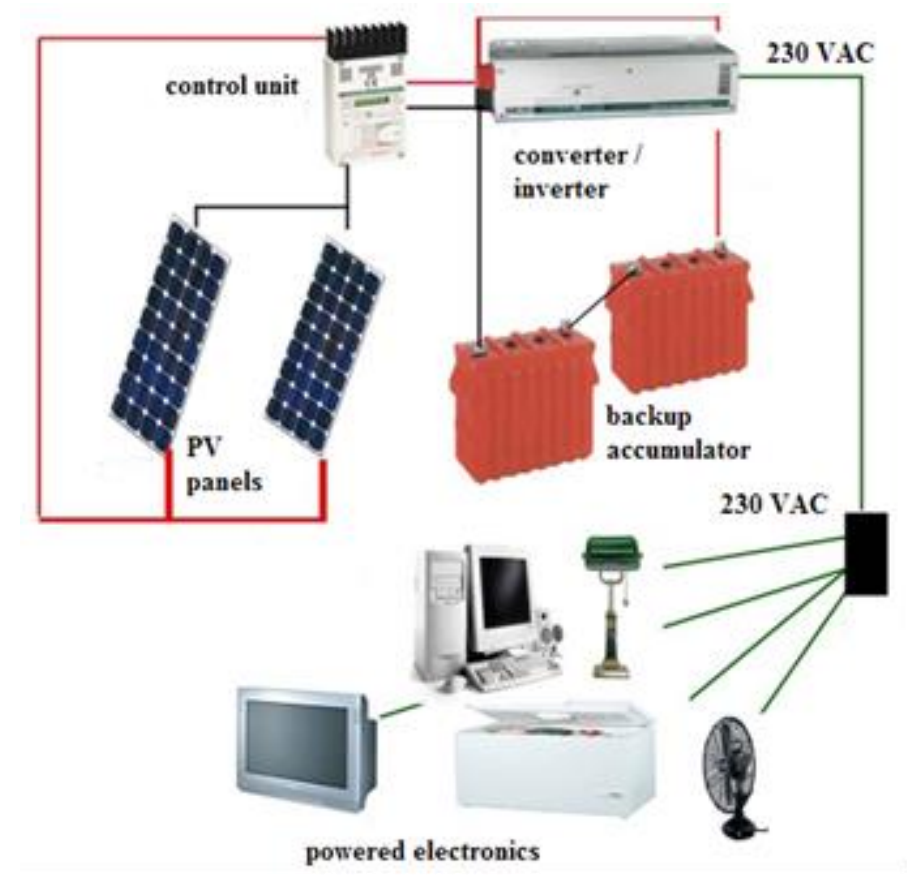

Fig. 2. Wiring scheme

Network systems are the most widespread in areas with a dense network of power lines. In the event that strikes the photovoltaic panels enough sunlight appliances are powered by solar energy and any excess is fed into the grid. If solar panels are unable to produce enough electrical power it is taken from the power grid.

\section{The influence of inclination and focus on efficiency photovoltaic panels}

If we want to make photovoltaic panels entrapped maximum sunlight throughout the day, we must use a floating structure that is going to turn, so that they are always to sunlight perpendicularly. The installation of such a device is relatively expensive and moreover it cannot be used in all cases, for example for roofs with a sloping cover. Another possibility is the installation of photovoltaic panels with a fixed orientation, but in this case we must accept the fact that the panels will not impinge upon the day maximum solar radiation. For the Czech Republic is the optimal inclination of photovoltaic panels 35_ oriented to the south, with deviation to the west is better than to the south. This is due to the fact that in the afternoon is usually more cloudiness, so there is less of the usable energy. In the long run south-facing photovoltaic panels have $5-7 \%$ higher production than that facing to the south-east. Only in the summer months is the production of panels oriented to south-east greater than or equal to the south-west. This is due to the fact that in the 
afternoon outside air has a higher temperature, so that the electiveness of south-facing photovoltaic panels decreases. The following Tab. 1 shows the ratio of the incident radiation for different inclination and orientation of the panels.

\begin{tabular}{cccccccc}
\hline \multirow{2}{*}{ Orientation } & & \multicolumn{7}{c}{ Angle } \\
& & $0^{\circ}$ & $25^{\circ}$ & $35^{\circ}$ & $45^{\circ}$ & $60^{\circ}$ & $90^{\circ}$ \\
\hline W & $90^{\circ}$ & $91.3 \%$ & $91.0 \%$ & $87.8 \%$ & $84.5 \%$ & $78.1 \%$ & $60.5 \%$ \\
WSW & $67.5^{\circ}$ & $91.3 \%$ & $94.8 \%$ & $93.7 \%$ & $91.2 \%$ & $85.3 \%$ & $66.4 \%$ \\
SW & $45^{\circ}$ & $91.3 \%$ & $97.8 \%$ & $98.1 \%$ & $96.3 \%$ & $90.6 \%$ & $70.2 \%$ \\
SSW & $22.5^{\circ}$ & $91.3 \%$ & $99.2 \%$ & $100.3 \%$ & $98.6 \%$ & $92.9 \%$ & $71.2 \%$ \\
S & $0^{\circ}$ & $91.3 \%$ & $99.0 \%$ & $100.0 \%$ & $98.2 \%$ & $92.3 \%$ & $70.0 \%$ \\
SSE & $-22.5^{\circ}$ & $91.3 \%$ & $97.4 \%$ & $97.5 \%$ & $95.4 \%$ & $89.2 \%$ & $67.5 \%$ \\
SE & $-45^{\circ}$ & $91.3 \%$ & $90.4 \%$ & $93.0 \%$ & $90.4 \%$ & $83.8 \%$ & $63.3 \%$ \\
ESE & $-67.5^{\circ}$ & $91.3 \%$ & $90.5 \%$ & $87.3 \%$ & $83.8 \%$ & $76.9 \%$ & $58.0 \%$ \\
E & $-90^{\circ}$ & $91.3 \%$ & $86.5 \%$ & $81,2 \%$ & $77.0 \%$ & $69.7 \%$ & $52.4 \%$ \\
\hline
\end{tabular}

Table 1. Ratio of incident radiation for different inclination and orientation - model Metronome Orientation Slope

Depicted Fi. 3 shows annual production of small photovoltaic power plant, which is located on the roof of the three-story building of Tomas Bata University in Zlin, Faculty of Applied Informatics and its angle of inclination from the horizontal plane is 45 with a south-east azimuth from normal. Photovoltaic panels used to power the experimental heating and cooling system, which is located in the Laboratory of Environment Engineering. The panels are made of polycrystalline photovoltaic cells. These panels have a manufacturer's declared energy efficiency of $15 \%$. When the intensity of solar radiation reaching the surface of the panels with a density of radiant flux of $750 \mathrm{~W}$ m- 2 should then be declared parameters of their electrical power consumption of approximately $\mathrm{P}=1265 \mathrm{~W}$.

\section{Production of electricity in 2014}

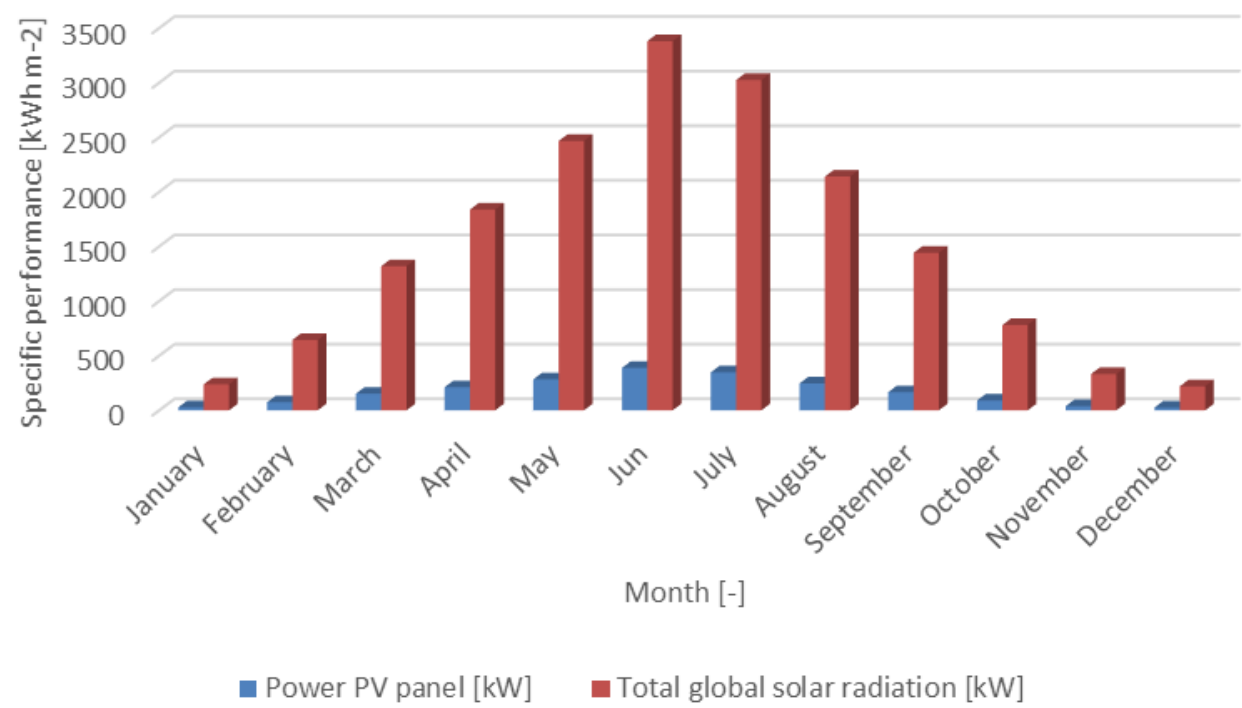

Fig. 3. Production of electricity in 2014

The Fig. 3 clearly shows that the highest electricity production is reached in the summer months. This orientation of photovoltaic panels was chosen because it produced electrical energy for usage to cool the Laboratory of Environmental Engineering.

Not only the orientation and angle of the photovoltaic panels influence the amount of electricity produced. There are other factors that affect the amount of produced electric energy as are pollution on surface of the panels and ageing of the panels. The last mentioned can be defined as the sum of irreversible changes in the material properties under given conditions. In our case, there are these changes as light, temperature, weather conditions and atmospheric gases which influence photovoltaic panels. These changes have a major impact on the efficiency of photovoltaic panels. For this reason, manufacturers indicate the service life of the panels, which manifests itself mainly by a decline in their effectiveness. Normally the manufacturer declared the assumption that after 10 years of operation the efficiency are reduce by $10 \%$ and after 25 years, $20 \%$ reduction of the original value. For this reason, an attempt was made, which aimed to find out how much it raises efficiency and thus the amount of electricity produced by photovoltaic panels far from the 
surface after removing dirt. This experiment was performed in cloudless day at the time between 11:14 am to 11:16 am when was the same light intensity as is shown in Table 2, an increase in efficiency was about $1 \%$ as can be seen in Figure 4 [11].

\begin{tabular}{cc}
\hline Time & $\begin{array}{c}\text { Solar radiation } \\
{\left[\mathrm{W} / \mathrm{m}^{2}\right]}\end{array}$ \\
\hline $10: 42$ & 331.80 \\
$10: 57$ & 331.91 \\
$11: 07$ & 354.61 \\
$11: 13$ & 354.62 \\
$11: 28$ & 354.63 \\
$11: 43$ & 354.63 \\
$11: 58$ & 354.62 \\
$12: 00$ & 334.71 \\
$12: 15$ & 334.08 \\
\hline
\end{tabular}

Table 2. Intensity of solar radiation

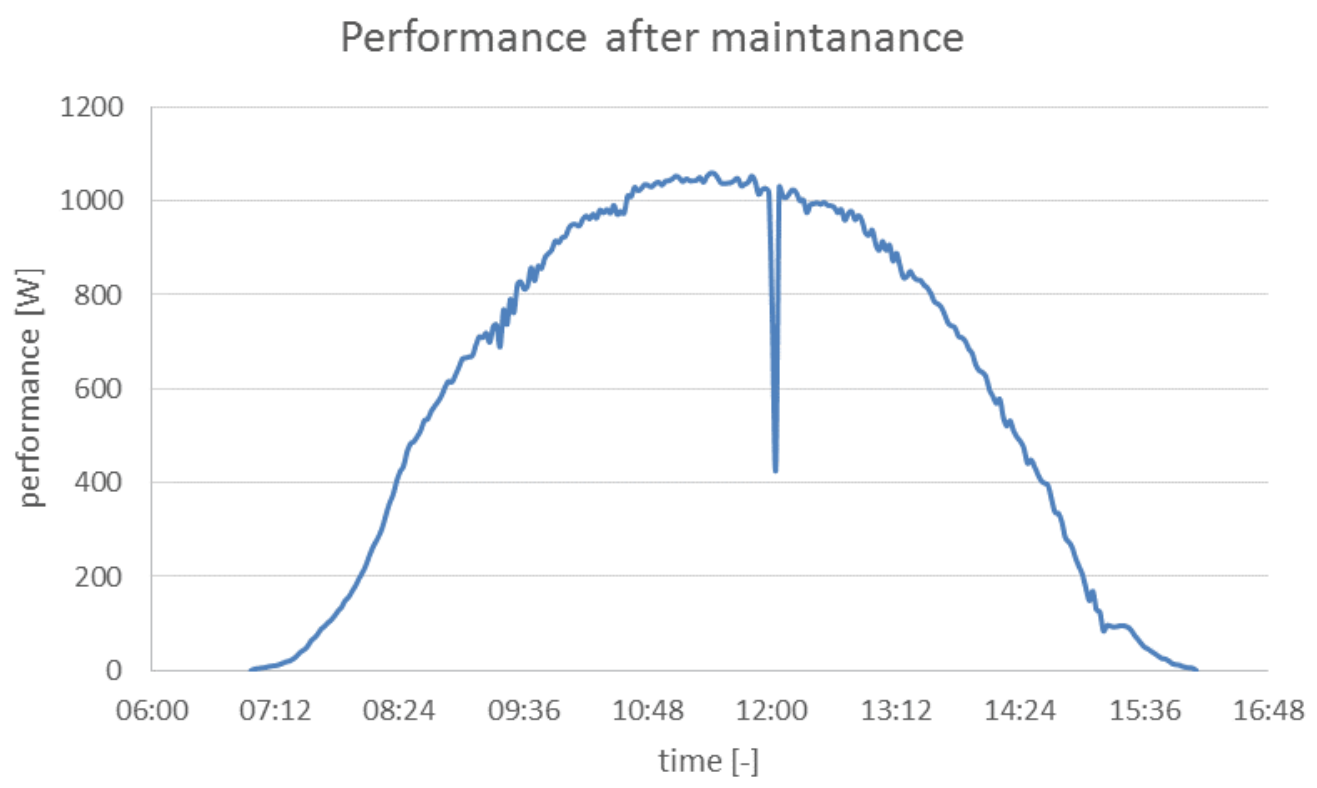

Fig. 4. Increased performance after maintenance [8]

\section{Conclusion}

The first part of this paper introduces the issue of electricity generation using photovoltaic panels. The quantity of produced electricity during the year, affected by many factors, not only the nature and location photovoltaic panels, as well as the climatic conditions in which the panels are located. Another part of this paper were presented with various options and application of photovoltaic systems, which are the most widespread in the world. It included the balance of the incident radiation for different inclination and orientation of panels and an example of production of electrical energy in already existing system for 2014. At the present system of verification was performed and what impact has the real conditions of surface contamination photovoltaic panels on their efficiency. From the measurement are revealed results that if the surface of photovoltaic panels will periodically stripped of layers of dirt, drops the fair efficiency due to contamination by about $1 \%$. The subject of our future research will be to determine the influence of various kinds of cloud and ambient weather conditions on the quantity produced electricity with photovoltaic panels.

\section{Acknowledgements}

The work was performed with financial support of research project NPU I No. MSMT-7778/2014 by the Ministry of Education of the Czech Republic and also by the European Regional Development Fund under the Project CEBIATech No. CZ.1.05/2.1.00/03.0089. Work was also supported in frame of Internal Grant Agency of Tomas Bata University in Zlin, Faculty of Applied Informatics No. IGA/CebiaTech/2015/002 and IGA/FAI/2015/022. 


\section{References}

[1] M. Quamruzzaman and K. M Rahman, A modified perturb and observe maximum power point tracking technique for single-stage gird-connected photovoltaic inverter, WSEAS Transactions on Power Systems, Vol.9, 2014, pp. 111-118.

[2] Stamatescu Iulia, Făgărăşan Ioana, Stamatescu Grigore, Arghira Nicoleta, Sergiu Stelian Iliescu. Design and Implementation of a Solar-tracking Algorithm. In: Procedia Engineering: Volume 69. 24th DAAAM International Symposium on Intelligent Manufacturing and Automation, 2013, s. 500-507. ISBN 978-1-84882-683-0.

[3] M. Quamruzzaman and K. M Rahman, A modified perturb and observe maximum power point tracking technique for single-stage gird-connected photovoltaic inverter, WSEAS Transactions on Power Systems, Vol.9, 2014, pp. 111-118.

[4] A. S. Oshaba and E. S. Ali, Bacteria foraging: A new technique for speed control of DC series Motor Supplied by photovoltaic System, WSEAS Transactions on Power Systems, Vol.9, 2014, pp. 185-195.

[5] J. Petera and J. Herman, Photovoltaics, available at: www.rescompass.org/IMG/pdf/Fotovoltaika.pdf (accessed on 2 March 2014)

[6] V. Kopunec, Analytic methods of photovoltaic panels and systems, available at: https://dspace.vutbr.cz/bitstream/handle/11012/1344/DIPLOMOVA\%20prace_V\%C3\%ADt_Kopunec.pdf?sequen $\mathrm{ce}=1$ (accessed on 7 April 2014)

[7] A. Bulletin. The present state and trends in the development of photovoltaic panels, available at:http://www.aldebaran.cz/bulletin/2010_37_fot.php (accessed on 15 March 2014)

[8] Complet Energy, Photovoltaic plants, available at:http://www.completenergy.cz/modules.php?name=News\&file=article\&sid=15 (accessed on 18 April 2014)

[9] T. Habrovansky. Control and monitoring of heating and cooling units in laboratory of building control systems, available at: http://dspace.k.utb.cz/handle/10563/ 6910 (accessed on 25 April 2014)

[10] Czech RE Agency, Photovoltaic inverter, available at: http://www.czrea.org/cs/ druhy-oze/fotovoltaika/fv-stridac (accessed on 16 April 2014)

[11] Solar Liglass, Photovoltaic panels, available at:http://www.solar-liglass.cz/fotovoltaicke-dotazy-a-odpovedi/47jaka-je-zivotnost-fotovoltaiky. (accessed on 28 April 2014) 